\title{
Negative association of $R$-Ras activation and breast cancer development
}

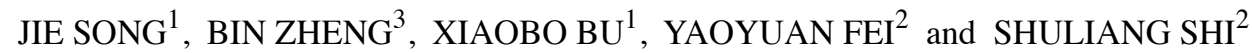 \\ ${ }^{1}$ Key Laboratory of Cancer Prevention and Treatment of Heilongiiang Province and Department of Biology, \\ Mudanjiang Medical University, Mudanjiang, Heilongjiang 157011; ${ }^{2}$ School of Life Science and Technology, \\ Harbin Institute of Technology, Harbin, Heilongjiang 150001, P.R. China; ${ }^{3}$ Center for Bioengineering and \\ School of Electrical and Computer Engineering, University of Oklahoma, Norman, OK 73019, USA
}

Received January 3, 2014; Accepted March 11, 2014

DOI: $10.3892 / o r .2014 .3121$

\begin{abstract}
R-Ras, a member of the Ras superfamily, is expressed in a wide variety of tissues and regulates cell adhesion, migration, differentiation and apoptosis. Research has raised the possibility that R-Ras may function as a positive regulator of cell proliferation and transformation in the breast. To understand the possible role of R-Ras in breast epithelial carcinogenesis, the expression and activation of R-Ras were detected in each of 69 pairs of breast cancer tissues and normal tumor-adjacent tissue samples by qRT-PCR, western blot analysis and GST pull down assay; 12 available cell lines were also subjected to western blot analysis and GST pull down assay. To further address the role of R-Ras in transformation-related phenotype formation of breast cancer cell line MCF-7 in vitro, R-Ras $38 \mathrm{~V}$, a constitutively activated mutant of R-Ras, was transfected into MCF-7 cells, and the cell proliferation, migration and cell cycle distribution were analyzed. The results showed that although there was slight difference in the protein expression of R-Ras between the breast cancer tissues and normal tissues, the activation of R-Ras was reduced in $63.8 \%$ of the cancer tissues when compared to the normal tissue samples. In addition, the results also showed that R-Ras38V inhibited cell proliferation, migration and cell cycle progression in the presence of serum. Contradicting the positive association reported in previous studies, our results indicate that R-Ras activation may negatively regulate the transformation of breast epithelial cells, and the loss of activation of R-Ras may be involved in
\end{abstract}

Correspondence to: Dr Jie Song, Key Laboratory of Cancer Prevention and Treatment of Heilongjiang Province and Department of Biology, Mudanjiang Medical University, Mudanjiang, Heilongjiang 157011, P.R. China

E-mail: 0453sj@163.com

Dr Shuliang Shi, School of Life Science and Technology, Harbin Institute of Technology, Harbin, Heilongjiang 150001, P.R. China

E-mail: liangss@hit.edu.cn

Key words: breast cancer, R-Ras, activation the carcinogenesis of breast cancer. To solve this controversy, further independent studies are needed to validate our study results.

\section{Introduction}

Breast cancer is a common cancer in women. It has a significant impact on the mental and physical health of females and it is also life-threatening. Due to the rapid societal and environment changes in China (i.e., increase in life expectancy and dietary structure or habit), the incidence of breast cancer in China has exhibited a yearly upward trend. The occurrence of breast cancer is the result of numerous factors, such as the activation of oncogenes and inactivation or reduced activity of tumor-suppressor genes, which trigger signal transduction pathway activation, leading to abnormal cell proliferation, abnormal apoptosis and abnormal structure, as well as expression of cell adhesion molecules. As a result, these factors promote tumor occurrence and development.

To date, many genes have been found to be associated with tumor carcinogenesis, such as ras, myc, sis, p53 and $R b$. Ras is a small GTPase, that plays an important role in diverse cellular reactions, particularly in the process of tumor genesis (1). The human $R$-Ras gene is isolated by low-stringency hybridization with a v-H-ras probe, and it is located on chromosome $19 q 13.3$ (2). As a member of the Ras superfamily of small GTPases, R-Ras plays a molecular switching role in cell signaling. The two interconvertible forms, GDP-bound inactive and GTP-bound active forms, transduce upstream signals to downstream effectors (3-5).

As it was originally cloned through its homologous $H$-Ras, the R-Ras protein has $55 \%$ similarity to H-Ras (2). R-Ras has close sequence similarities, and an almost identical effectorbinding region to $\mathrm{H}-, \mathrm{N}$ - and K-Ras (6), and has common Ras effectors, including RalGDS and PI3-kinase (7). The R-Ras protein has 26 amino acids in its $\mathrm{N}$ - terminal, thus R-Ras has distinct cellular functions from other analogous Ras members.

$\mathrm{R}$-Ras is an important molecule. R-Ras was found to regulate the apoptotic response in hematopoietic 32D.3 cells. R-Ras (38V) inhibits BCL-2-mediated apoptotic cell death $(8,9)$. In addition to its distinct functions, R-Ras affects integrin activation by controlling the ligand-binding activity of integrins. 
R-Ras activates integrins, resulting in increased cell adhesion and matrix assembly $(10,11)$. For example, active R-Ras $(38 \mathrm{~V})$ promotes the formation of focal adhesion and a spread cell shape (12). A proline rich site is required for controlling cell adhesion $(13,14)$. Dominant active R-Ras promotes neurite outgrowth of late embryonic retinal neurons; R-Ras inactivation is required to induce growth cone collapse (15). It was shown that R-Ras is essential for axon specification and neuronal polarization in hippocampal neurons, thus it is also implicated in the promotion of neurite outgrowth. The role of R-Ras has also been identified as an important regulator of vascular regeneration in vivo (16). In a study by Komatsu et al, R-ras gene disruption in mice rendered these animals susceptible to the excessive proliferative response of neointimal smooth muscle cells to acute arterial injury (16). Although R-Ras promotes normalization of tumor vasculature (17-19), it is a small GTPase of the Ras family that can perform multiple functions including the regulation of cell apoptotic and integrin activity, cell motility, neural synaptic plasticity and vascular regeneration.

Transforming growth factor- $\beta$ (TGF- $\beta$ ) was found to cooperate with R-Ras to promote murine EpH4 cell transformation and tumor progression (21), and R-Ras also reportedly induced a more invasive phenotype in breast epithelial cells through integrin. In addition, R-Ras activation was found to disrupt the polarized differentiation of breast epithelial cells through collagen (22). R-Ras promotes estrogen-independent growth when EGF receptor family members are not involved in breast cancer cells. Research has found that p130 (Cas) regulates the activity of AND-34 to control R-Ras-GTPases that may participate in the progression of breast cancer cells to tamoxifen resistance (23). R-Ras and BCAR3 regulate the level of IRS-1 protein in estrogen-dependent MCF-7 and ZR75 breast cancer cells. The expression of a constitutively activated R-Ras mutant, R-Ras38V or of BCAR3 accelerates the degradation of IRS-1 leading to the impairment of signaling. Both R-Ras38V expression and estrogen signaling blockade lead to the degradation of IRS-1 (24); however, the transforming properties of R-Ras remain under investigation, and are partially dependent on the specific cell in question.

Although R-Ras has been suggested to function in breast cancer cell lines, its main mechanisms remain unclear. The level of R-Ras expression and its activity level in breast cancer in particular have not yet been reported. Thus, the present study was designed to explore the role of R-Ras in breast cancer. The overall objective of the present study was to investigate and better understand the association between R-Ras activity and breast cancer development. The detailed description of our experimental procedures and results are reported in the following sections of the present study.

\section{Materials and methods}

Testing materials. In this in vitro study, our testing materials were selected from two sources. The first included available cancer-related cell lines. A total of 12 different types of cell lines were selected. Among them, MCF-10A is a normal breast cell line, while MCF-7, T47D, MDA-MB-453, MDA-MB-435S, BT474, ZR-75-30, SK-BR-3, Hs578T, MDA-MB-231, Bcap37 and BT549 are mammary carcinoma cells. These cells were a gift from the Laboratory of Tumor Molecular Cell Biology, Harbin Institute of Technology University. MCF 10A (ATCC CRL no. 10317), MCF-7 (ATCC HTB no. 22), MDA-MB-231 (ATCC HTB no. 26), MDA-MB-453 (ATCC HTB no. 131), MDA-MB-453S (ATCC HTB no. 129), BT-474 (ATCC HTB no. 20), ZR-75-30 (ATCC CRL no. 1504), SK-BR-3 (ATCC HTB no. 30), Hs578T (ATCC HTB no. 126), BT-549 (ATCC HTB no. 122) were purchased from the American Type Culture Collection. BCap37 was purchased from the Cell Bank of the Chinese Academy of Science (32). The cells were grown in Dulbecco's modified Eagle's medium (DMEM; Gibco-BRL, Grand Island, NY, USA) supplemented with $10 \%$ heat-inactivated fetal bovine serum (FBS; Gibco-BRL) and $20 \mu \mathrm{M}$ glutamine.

The second source consisted of tissue samples selected from resected breast tumors. The tissue samples were acquired from 69 breast cancer patients who underwent breast surgery at Mudanjiang Cancer Hospital, China. From each resected breast region of one patient, one pair of tissues was acquired. This included one malignant tissue sample acquired inside the confirmed cancer tumor and one negative (normal) breast tissue sample located outside the tumor region. All of the tumor tissues were obtained at primary resection, and the adjacent non-tumor tissue was removed at least $5 \mathrm{~cm}$ from the tumor border. These samples were immediately transferred to liquid nitrogen. Histologic diagnosis was carried out by standard evaluation. The classification of the human breast tumors used in the present study was based on the revised World Health Organization criteria for tumors. As a result, our breast tissue testing dataset included 69 pairs of malignant and normal breast tissue samples acquired from 69 cancer patients.

In this testing dataset, the patient ages ranged from 29 to 74 years with an average age of 45.38 years. The clinicopathological data indicated that the majority of the 64 patients presented with infiltrative ductal carcinoma, while the remaining 5 women had other types of cancers including infiltrative lobular carcinoma (1 case), mucinous carcinoma (1 case), medullary carcinoma ( 2 cases) and intraductal carcinoma (1 case). Among the patients, 42 did not have lymph node metastasis, while 27 had lymph node metastasis. The measured resected tumor sizes varied in these patients. Among them, 21 tumors had a measured diameter $<2 \mathrm{~cm}$ and 48 tumors had a diameter $>2 \mathrm{~cm}$. The histologic tests showed that 53 tumors had histologic grades 1-2 and 16 had histologic grades 2-3. None of the patients had been subjected to chemotherapy or radiation therapy prior to tumor resection. There were no pre-selection requirements except that the tumor diameter exceeded $1 \mathrm{~cm}$ in size, as this was more likely to provide sufficient study material. The same tissue was divided into three parts for use in the western immunoblot analysis, qPT-PCR and GST pull down assay. We then selected a set of antibodies and reagents for this study. These included: i) rabbit anti-R-Ras antibodies produced by Santa Cruz Biotechnology (Santa Cruz, CA, USA); ii) monoclonal mouse monoclonal anti-GAPDH antibody from the Protein Tech Group; and iii) the Glutathione Sepharose ${ }^{\mathrm{TM}}$ 4B (Amersham Biosciences) RNA extraction kits and reverse transcription kits from Tiangen Biotech Co., Ltd. (Beijing, China). The PCR primers were designed using Beacon Designer and synthesized by Beijing SBS Genetech Co., Ltd. (Beijing, China). Custom-made Hot-Start Master 
mixture for quantitative PCR was also obtained from Abgene (Takara-Applied Biosystems, Shiga, Japan).

Ethics statement. All of the cell line studies and the tissue collection protocol were carried out in strict accordance with the Helsinki Declaration and the International Ethical Guidelines for Biomedical Research involving Human Subjects. All patients signed an informed consent in regards to surgical removal, tumor therapy and the use of the residual material. Concerning the present study, the Mudanjiang Medical University Ethics Committee reviewed and approved conduction of this research.

\section{Methods}

Cell transfection. The cells were first transfected using the cationic liposome method with $4 \mu \mathrm{g}$ of plasmid for each culture dish. After transfection, the cells were cultured in OPTI-MEM for $48 \mathrm{~h}$. The medium was then replaced with fresh medium containing $0.6 \mathrm{mg} / \mathrm{ml}$ geneticin (G418; Gibco-BRL), and the cultured cells were continually selected for stable transfectants. Up to resistance clone formation, the cells were subcultured until enough cells were obtained for subsequent experiments. The cells were always maintained in medium with G418 substance. The R-Ras-GTP protein and R-Ras protein were constantly expressed. All clones expressed the R-Ras mutant protein at similar levels, as indicated by western blot analysis.

Testing and data analysis methods. In order to avoid or minimize the potential bias of the experimental results, we applied six testing methods in the present study to cross-validate the experimental results and increase data analysis power. Five were used in cell line tests and three were applied in tumor sample tests. Following are the brief description of each testing method.

Cell proliferation ability. After transfection, the first testing method was assessment of cell proliferation ability. MCF-7 cells in a logarithmic growth phase were suspended in RPMI-1640 containing 10\% fetal bovine serum (FBS). The cells were inoculated in 24 -well plates, with $\sim 1 \times 10^{4}$ cells in each plate. After the cells had grown for $24 \mathrm{~h}$, and had adhered to the plate, the cells were treated with replaced serum-free medium. After cultural synchronization for $24 \mathrm{~h}$, the cells were treated with $1 \%$ FBS medium. The medium was replaced every two days.

Cell counts were then performed from two replicate wells on day 1, 4, 7 and 10, respectively; at the same time the living cells were confirmed by trypan blue staining. The repeated test mean data was input into GraphPad Prism.5.0, and a chart for the growth curve was plotted.

Cell cycle analysis. After the MCF-7 cells stably expressed pcDNA3.1, pcDNA-R-Ras or pcDNA-R-Ras38V, the cell cycle stages were determined by the second testing method using flow cytometric analysis. The cells were cultured at $37^{\circ} \mathrm{C}$ with $5 \% \mathrm{CO}_{2}$ in DMEM containing $10 \%$ FCS. For convergence at a rate of $\sim 80 \%$, the cells were digested by trypsin, and made into a suspension. Then, the cells were centrifuged at 1,500 rpm for $5 \mathrm{~min}$ at $4^{\circ} \mathrm{C}$. The supernatant was discarded, and the cells were resuspended in PBS buffer. After the mixture was repeatedly centrifuged, we discarded the supernatant. The cells were resuspended in $70 \%$ ethanol $\left(-20^{\circ} \mathrm{C}\right)$ and stored at $-20^{\circ} \mathrm{C}$ for at least $12 \mathrm{~h}$. Once the above processes were completed, we repeated centrifugation of the cells and washed them twice with cold PBS. Cells were then stained with propidium iodide (PI) staining solution, which was constructed by adding three chemical components [10 ml of $0.1 \%$ NP-40, $1 \mathrm{mg}$ DNase-free RNase (Sigma) and $500 \mu \mathrm{g} / \mathrm{ml} \mathrm{PI}]$ into $0.1 \%$ PBS. After the stained cells were store at $-20^{\circ} \mathrm{C}$ away from light for $\sim 15 \mathrm{~min}$, the cells were centrifuged at $1,500 \mathrm{rpm}$ for $5 \mathrm{~min}$ at $4^{\circ} \mathrm{C}$, for removal of PI. The processed cells were then resuspended in $500 \mu \mathrm{l}$ PBS buffer and were ready for flow cytometry. After this cell preparation process, we used a flow cytometry device to acquire and record the cell signal spectrum data.

Cell migration assay. The preprocessed and cultured cells were also transfected and plated on dishes. We then conducted the third test based on a cell migration assay. After convergence at a rate of $\sim 80 \%$, the cells were treated only with serum for $16 \mathrm{~h}$. The cells were trypsinized, followed by termination digestion using serum containing DMEM. The cells were completely formed into a single-cell suspension at a concentration at $5 \times 10^{5} / \mathrm{ml}$. After the cells were spread on the bottom of Transwells coated with collagen $\mathrm{I}$ at $37^{\circ} \mathrm{C}$ in $5 \% \mathrm{CO}_{2}$ and stored for $20 \mathrm{~h}$, we scratched the cell monolayers with a pipette tip. The Transwells were then placed in methanol for $5 \mathrm{~min}$ and finally stained using $1 \%$ crystal violet for $2 \mathrm{~min}$. The cells that had migrated to the lower side of the Transwells were visually counted with a microscope using an objective lens at x20 magnification.

The above three testing methods were applied only to the cell lines. The following two methods were applied to both cell lines and tumor specimens.

Western immunoblot analysis. The fourth testing method was western immunoblot analysis. For tumor specimen processing, we extracted a $150 \mathrm{mg}$ specimen from each case. It was crushed in liquid nitrogen and lysed on ice for $10 \mathrm{~min}$ in lysis buffer containing $50 \mathrm{mM}$ Tris $\mathrm{pH} 7.6,2.5 \mathrm{mM} \mathrm{MgCl}_{2}$, $10 \mathrm{mM}$ NaF, $1 \%$ Triton $\mathrm{X}-100$ and $10 \%$ glycerol by adding $1 \mathrm{mM}$ PMSF, $1 \mu \mathrm{M}$ pepstatin, $0.2 \mu \mathrm{M}$ aprotinin and $4 \mu \mathrm{M}$ leupeptin (Sigma). The cell lines were lysed using the same buffer. Protein concentrations inside the lysis buffer were initially measured by NanoDrop 2000. Then, by adaptively adjusting the lysis buffer concentration level, we obtained the equivalent amounts of protein for all testing samples. Finally, we extracted a $100 \mu \mathrm{g}$ sample from the lysates of each case prepared for western blot analysis, while the rest were used for the fifth testing method, the GST-pull down assay (as discussed in the next paragraph). In the western blot analysis, the samples were resuspended in $2 \mathrm{X}$ loading buffer (mixed with $50 \mathrm{mmol} / \mathrm{l}$ Tris-HCl, pH 6.8, 10\% sodium dodecyl sulfate, $10 \%$ glycerol, $0.001 \%$ bromophenol blue), and then denatured with 2-mercaptoethanol (Sigma). In order to perform western blot analysis for R-Ras from the available samples, $15 \mu \mathrm{g}$ of protein was separated by $12 \%$ sodium dodecyl sulfate (SDS)polyacrylamide gel electrophoresis. The bands were then electrically transferred onto PVDF membranes (Millipore) using Semi-Dry Trans-Blot Cell (Bio-Rad Laboratories, Hercules, CA, USA). Finally, protein loading was controlled by blotting the same membrane with an anti-GAPDH antibody.

GST-pull down assay. The fifth testing method, a GST-pull down assay, was also applied to the cell lines and the tumor specimens. This technique requires multiple steps 
for preprocessing the testing materials. The first step is to produce the induced protein using the following processes. i) GST-RaLGDS-RBD vectors were transformed into BL21 bacteria. ii) BL21 (DE3) E. coli were individually transformed with the expression vectors and grown overnight at $37^{\circ} \mathrm{C}$ on Luria-Bertani broth (LB)-agar plates with $100 \mu \mathrm{g} / \mathrm{ml}$ ampicillin. iii) Approximately 1 colony was transferred into $5 \mathrm{ml} \mathrm{LB}$ broth with $100 \mu \mathrm{g} / \mathrm{ml}$ ampicillin and grown at $37^{\circ} \mathrm{C}$ overnight. iv) Bacterial LB broth (1 ml) was transferred into $100 \mathrm{ml} \mathrm{LB}$ broth with $100 \mu \mathrm{g} / \mathrm{ml}$ ampicillin and grown at $37^{\circ} \mathrm{C}$ for $3-4 \mathrm{~h}$ to a bacterial density of $0.5-0.6$ absorbance units at $600 \mathrm{~nm}$. v) The transformed bacteria were cultured in LB broth with the addition of $0.5 \mathrm{mM}$ of IPTG to induce GST-fusion protein expression at $30^{\circ} \mathrm{C}$ for $3 \mathrm{~h}$. vi) The bacterial cells expressing the fusion proteins were finally collected by centrifugation and placed into tubes that were quickly frozen at $-20^{\circ} \mathrm{C}$.

The second step was to bind the induced protein and beads using the following processes. i) The beads were resuspended in buffer mixed with (pH 7.6): $50 \mathrm{mM}$ Tris, $2.5 \mathrm{mM}$ $\mathrm{MgCl}_{2}, 10 \mathrm{mM} \mathrm{NaF}, 1 \%$ Triton X-100, $10 \%$ glycerol, $1 \mathrm{mM}$ of phenylmethylsulfonyl fluoride (PMSF) (Sigma) at $4^{\circ} \mathrm{C}$. ii) The bacterial mixture was then lysed using a sonicator at a $100 \mathrm{~W}$ setting ' 4 ' with 12 bursts of $3 \mathrm{sec}$ at $4^{\circ} \mathrm{C}$. The lysates were cleared by centrifugation at $8,000 \mathrm{x} \mathrm{g}$ for $20 \mathrm{~min}$. iii) The GST-fusion proteins were purified by $0.2 \mathrm{ml}$ columns of Glutathione Sepharose 4B beads (Amersham Biosciences). The beads were then suspended by rotating at $4^{\circ} \mathrm{C}$ for $3 \mathrm{~h}$. The affinity columns were rinsed 5 times with $0.75 \mathrm{ml}$ of washing buffer (consisting of $\mathrm{pH} 7.6 ; 50 \mathrm{mM}$ Tris, $2.5 \mathrm{mM} \mathrm{MgCl}$, $10 \mathrm{mM} \mathrm{NaF}, 1 \%$ Triton X-100 and $10 \%$ glycerol). The third step was to bind the tissue sample and the beads processed in the second step. Specifically, every $0.4 \mathrm{ml}$ of tissue extracts from the samples that were described in the western blot analysis were mixed with $50 \mu \mathrm{l}$ of the beads. We also performed suspension by rotating the final mixture at $4^{\circ} \mathrm{C}$ for $1 \mathrm{~h}$. After the beads were washed for three times in the same washing buffer and boiled in 1X SDS loading buffer, the GST-proteins were collected by centrifugation. The pull-down samples were also tested using western blot analysis for R-RasGTPase.

Quantitative RT-PCR. Our final (sixth) testing method was only applied to the tumor tissue samples. The sixth testing method used a quantitative RT-PCR method in which total RNA extraction from the tissue specimens was performed according to the instruction manual by Tiangen Biochemical Technology. The RNA quality was evaluated by electrophoresis on $1.2 \%$ agarose gel. The RNA samples were quantified, and similar quantities were used for cDNA synthesis. For the cDNA synthesis, $1 \mu \mathrm{g}$ of total RNA was reverse-transcribed using oligo-dT and the Superscript amplification system. Quantitative RT-PCR was carried out using SYBR-Green PCR Master Mix. R-Ras (NM 006270) had the sense primer, 5'-CCTGCTGGTGTTCGCCATTA-3' and the antisense primer, 5'-GGTCCTTGACCCGCAGAATC-3'; while GAPDH (NM_002046) had the sense primer, 5'-GCACCGTCAAG GCTGAGAAC-3' and antisense primer, 5'-TGGTGAAGA CGCCAGTGGA-3'. The cycling conditions were set at $95^{\circ} \mathrm{C}$ for $10 \mathrm{sec}$, followed by $95^{\circ} \mathrm{C}$ for $5 \mathrm{sec}, 60^{\circ} \mathrm{C}$ for $31 \mathrm{sec}$ for 40 cycles. For quantification, the target genes were normalized to the internal standard GAPDH gene. The amplification efficiency was calculated for each gene from the slope of the linear regression curve of $\mathrm{Ct}$ values vs. logarithm (log) of the cDNA concentration. The PCR efficiency in the exponential phase was calculated. Relative expression levels were also calculated.

After acquiring all testing data from the cell lines and the paired breast tissue specimens using all six testing methods, we conducted statistical data analysis using the Student's t-test and one-way ANOVA. In the data analysis, $\mathrm{P}<0.05$ was used as an index to determine statistical significance. All computations were carried out using the SPSS 13.0 statistical program.

\section{Results}

Western blot analysis of total R-Ras and R-Ras-GTP expression in the 12 cell lines. We measured R-Ras protein levels and compared the R-Ras expression levels between the normal breast MCF-10 cell line and 11 mammary carcinoma cell lines using western blot analysis. We found that the R-Ras protein expression levels were lower in 8 mammary carcinoma cell lines (MCF-7, MDA-MB-435S, BT474, ZR-75-30, Hs578T, SK-BR-3, BT549 and MDA-MB-231) than the level in the MCF-10 cell line (Fig. 1A and B). The R-Ras protein expression level was decreased in $72.7 \%$ of the 11 mammary carcinoma cell lines. The results also showed that by comparing the expression level of R-Ras active protein in MCF-10 cells with the other 11 mammary carcinoma cell lines using both western blot analysis and GST-pull down assay, R-Ras active protein was expressed in 9 of the 11 breast carcinoma cell lines (MCF-7, MDA-MB-453, T47D, MDA-MB-435S, BT474, ZR-75-30, SK-BR-3, BT549 and MDA-MB-231) and was lower than that in the MCF-10 cells (Fig. 1A and C). The level of R-Ras active protein decreased in $81.8 \%$ of mammary carcinoma cell lines.

qRT-PCR and western immunoblot analysis of R-Ras expression in the breast cancer and paired normal tumoradjacent tissues. To confirm the results of R-Ras expression in the breast cell lines, 42 samples of breast cancer and paired normal tumor-adjacent tissues were selected and analyzed by quantitative real-time RT-PCR. The R-Ras expression profiles were determined and normalized against GAPDH in order to correct for varying tissues between samples. R-Ras was found to be expressed in both normal tissues and breast cancer specimens. The median relative R-Ras mRNA ratio was 3.1365 (range, 0.2207-9.6078) for normal tumor-adjacent tissues, and 0.5454 (range, 0.0038-4.0000) for cancer tissues. The data demonstrated that the expression level of R-Ras mRNA in the breast cancer tissues was significantly lower than that in the normal breast tissues $(\mathrm{P}=0.00000, \mathrm{P}<0.01)$ (Fig. 2). When using western immunoblot method to detect and analyze 69 samples of breast cancer and paired normal tumor-adjacent tissues, the R-Ras expression profiles were determined and normalized against GAPDH (Fig. 3A). Although the results showed that R-Ras was positively expressed in all normal tissues and 67 breast cancer specimens, on the whole, the level of R-Ras protein in 57 cases of cancer tissues was significantly lower than that in the normal tissues $(\mathrm{P}=0.00000, \mathrm{P}<0.0001)$ (Fig. 3B). The R-Ras protein levels in the samples demonstrated a similar expression pattern as compared to those of the R-Ras mRNA. The method proved that the expression level of total 

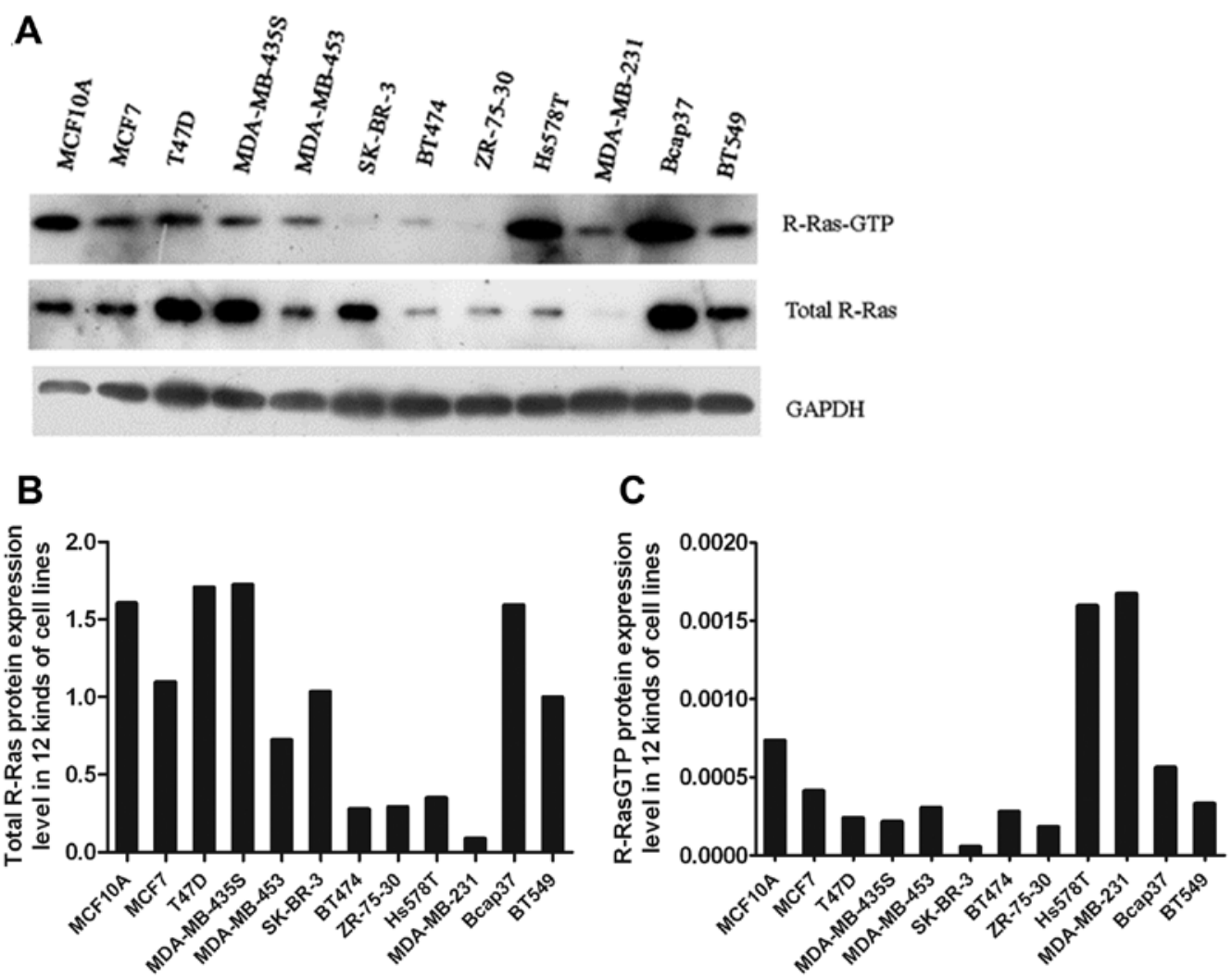

Figure 1. R-Ras protein expressed in 12 breast cell lines. (A) Western blot analysis of endogenous R-Ras in 11 human breast cancer cell lines and one normal human breast epithelial cell line. The total protein extracted from the indicated cell lines was analyzed using a polyclonal antibody against human R-Ras. GAPDH was used as a loading control. (B) The graph indicates the levels of total R-Ras expression compared to the expression of GAPDH. (C) The graph indicates the levels of R-Ras-GTP expression compared with the expression of total R-Ras and GAPDH.

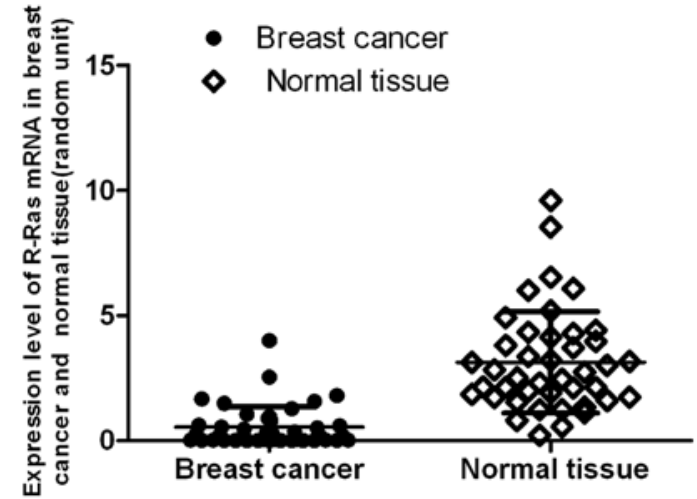

Figure 2. Endogenous mRNA levels of the R-Ras gene were measured by qRT-PCR analysis of total breast tissue RNA. Data were normalized to GAPDH mRNA levels. Error bars represent SD $(n=42)$. P-values calculated using the Student's t-test are indicated. $\mathrm{P}<0.05$.

R-Ras protein was decreased in the breast cancer specimens, with a rate of decrease of $82.6 \%$. Collectively, the three testing methods and results proved that the expression level of total $\mathrm{R}$-Ras protein was in general lower in the breast cancer-related cell lines and the actual tissue specimens.

Analysis of the activation of R-Ras in the tissues. R-Ras molecules cycle between the active GTP-bound form and the inactive GDP-bound form; the amount of active GTP-Ras was separated from these samples, and was measured as previously described using western immunoblot analysis. The activation of R-Ras-GTP expression levels was determined and normalized against R-Ras-total/GAPDH. In the 69 breast cancer tissue samples and paired normal tumor-adjacent tissues, 54 of $69(78.3 \%)$ normal tumor-adjacent tissue samples displayed R-Ras-GTP expression (Fig. 3A). There were 14 paired cases of breast cancer and normal tissues without expression of R-Ras; 10 of 69 (14.5\%) breast cancer tissue samples displayed R-Ras-GTP expression. The activity in the normal tumor-adjacent tissues was $\sim 6$-fold that in the breast cancer tissue samples. The activity of R-Ras in the breast cancer tissue samples was lower than that in the normal tissues; the degree of R-Ras activation was significantly lower than that in the the normal tissues $(\mathrm{P}=0.011 ; \mathrm{P}<0.05)$ (Fig. 3C). Although $\mathrm{R}$-Ras activation was positively expressed in 10 breast cancer samples, there were only 4 cases in which the activation level was higher than that in the corresponding adjacent normal tissue. They were all infiltrative ductal carcinoma with lymph node metastasis and negative PR.

Phenotype formation of breast cancer cell line transfected with $R$-Ras and R-Ras $38 \mathrm{~V}$. To further address the role of $\mathrm{R}$-Ras in transformation-related phenotype formation in breast cancer cells, R-Ras and R-Ras $38 \mathrm{~V}$, which is a constitutivelyactivated mutant of R-Ras, were transfected into MCF-7 cells (Fig. 4A), and cell proliferation, migration and cell cycle phases were analyzed. After the MCF-7 cells were transfected 
A-1

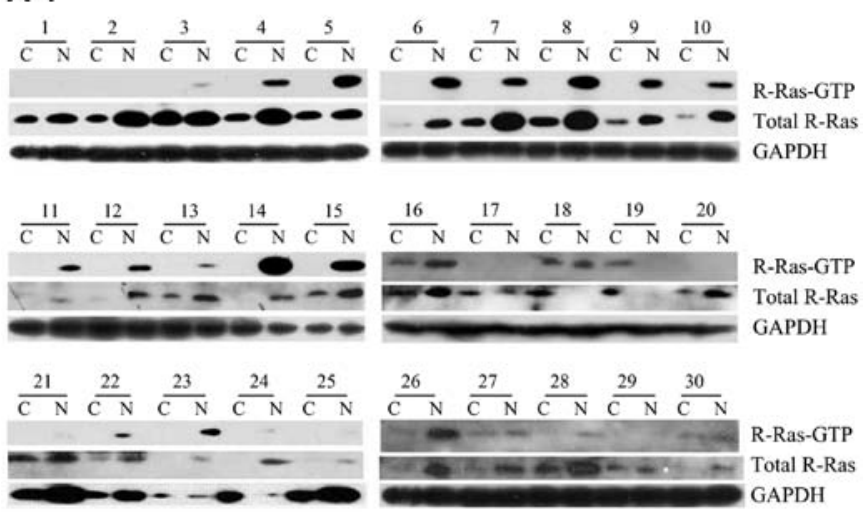

A-2
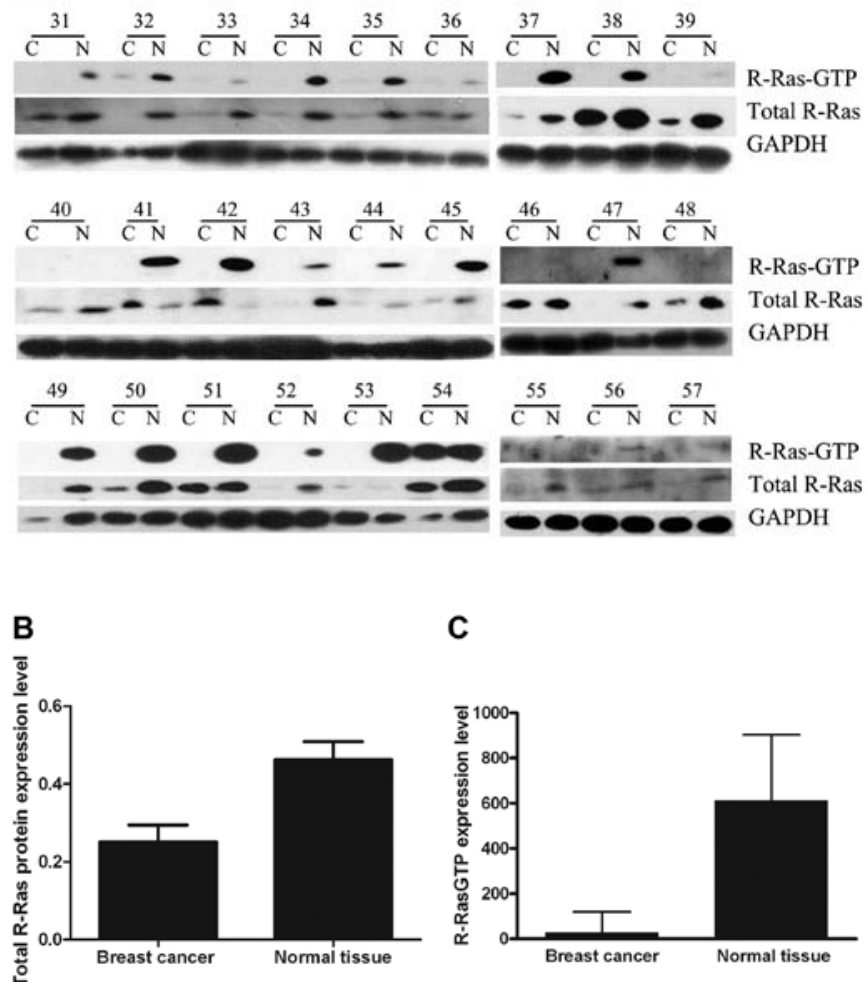

Figure 3. Total R-Ras and R-Ras-GTP protein expressed in breast tissues. (A1-A3) Western blot analysis of endogenous total R-Ras protein and R-Ras-GTP protein insufficiency in human breast cancer tissues and its abundance in normal breast tissues. The total R-Ras protein was extracted from the indicated tissue, R-RasGTP protein was separated by GST-pull down assay with Glutathione Sepharose ${ }^{\mathrm{TM}}$ 4B beads, and samples were resolved using $12 \%$ SDS-PAGE gels. Blots were probed with polyclonal human R-Ras antibodies (top panel and middle panel), and GAPDH antibodies (bottom panel). Data was analyzed using GAPDH as a loading control. (B) The bar graph indicates the level of total R-Ras expression compared with the expression of GAPDH. (C) The bar graph indicates the level of R-RasGTP expression compared with the expression of total R-Ras and GAPDH. Error bars reflect the standard error from independent experiments.

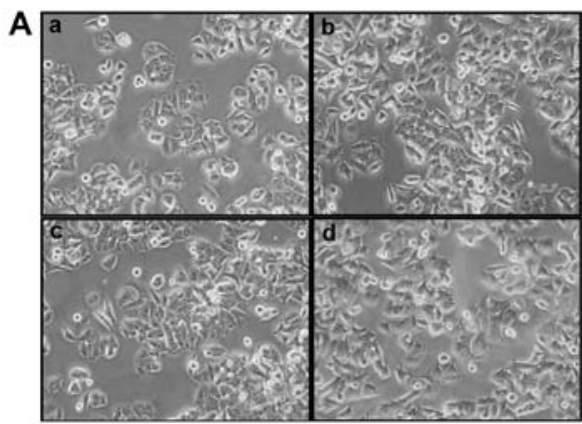

C

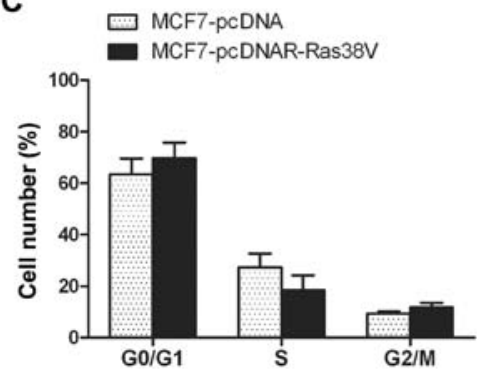

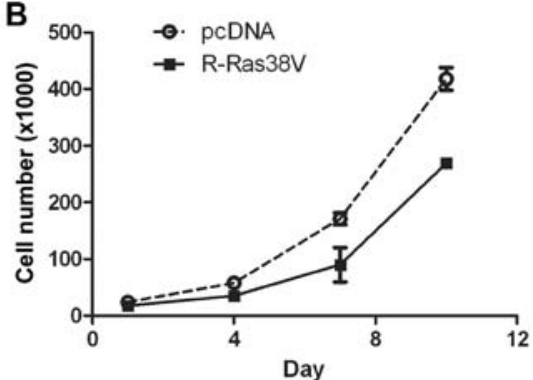

D

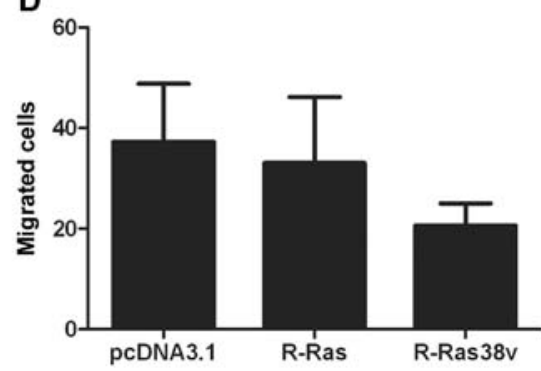

Figure 4. Overexpression and overactivation of R-Ras inhibits MCF-7 cell proliferation, DNA replication and migration. (A) Images of MCF-7 cell clones following stable transfection: a, MCF-7; b, MCF-7-pcDNA3.1; c, MCF-7-pcDNA3.1R-Ras; d, MCF-7-pcDNA3.1R-Ras38V. (B) Following the transfection of MCF-7 cells with pcDNA3.1R-Ras, proliferation of MCF-7 cells was inhibited. (C) Cell cycle phase distribution was assessed by flow cytometry. The cell cycle of MCF-7 cells transfected with pcDNA3.1R-Ras38V was arrested in S phase. (D) R-Ras inhibited cell migration. Vector-transfected MCF-7 cells (vector), activated R-Ras-transfected MCF-7 cells (R-Ras38V), or R-Ras-transfected MCF-7 cells were placed in collagen I-coated Transwell filters ( $8 \mu \mathrm{m}$ pores). After $24 \mathrm{~h}$, following migration through the filters, cells on the underside of the filter were stained and counted. The mean count of 10 visual fields was determined. Data shown are the mean \pm standard error values from experiments that were conducted in duplicate. 
Table I. Relationship between total R-Ras protein expression and clinicopathological characteristics of breast cancer cases.

\begin{tabular}{|c|c|c|c|}
\hline Parameters & $\begin{array}{l}\text { Cases } \\
\text { (n) }\end{array}$ & $\begin{array}{c}\text { R-Ras/GAPDH } \\
\text { mean } \pm \mathrm{SD}\end{array}$ & P-value \\
\hline Age (years) & & & 0.1296 \\
\hline$<50$ & 37 & $0.20 \pm 0.06$ & \\
\hline$\geq 50$ & 32 & $0.30 \pm 0.21$ & \\
\hline Diameter of tumor $(\mathrm{cm})$ & & & $0.0002^{\mathrm{a}}$ \\
\hline$<2$ & 21 & $0.42 \pm 0.23$ & \\
\hline$\geq 2$ & 48 & $0.11 \pm 0.21$ & \\
\hline Histologic type & & & 0.3803 \\
\hline Ductal carcinoma & 64 & $0.25 \pm 0.14$ & \\
\hline Others & 5 & $0.20 \pm 0.01$ & \\
\hline Lymph node metastasis & & & $0.0474^{\mathrm{a}}$ \\
\hline Without & 27 & $0.34 \pm 0.26$ & \\
\hline With & 42 & $0.19 \pm 0.04$ & \\
\hline Histologic grades & & & 0.2358 \\
\hline I-II & 53 & $0.31 \pm 0.11$ & \\
\hline II-III & 16 & $0.23 \pm 0.15$ & \\
\hline PR status & & & 0.6161 \\
\hline- & 38 & $0.26 \pm 0.17$ & \\
\hline+ & 17 & $0.30 \pm 0.12$ & \\
\hline++-+++ & 14 & $0.17 \pm 0.06$ & \\
\hline ER status & & & $0.0159^{\mathrm{a}}$ \\
\hline- & 31 & $0.18 \pm 0.04$ & \\
\hline+ & 11 & $0.21 \pm 0.04$ & \\
\hline++ & 21 & $0.26 \pm 0.12$ & \\
\hline+++ & 6 & $0.73 \pm 0.90$ & \\
\hline
\end{tabular}

PR, progesterone receptor; ER, estrogen receptor. ${ }^{\mathrm{a}} \mathrm{P}<0.05$ is considered significant.

with pcDNA3.1 or pcDNA3.1R-Ras for 3 days, the rate of cell proliferation declined to $35-40 \%$. The results showed that R-Ras inhibited cell proliferation (Fig. 4B). Cell cycle phase distribution was assessed by flow cytometry. after the
MCF-7 cells were transfected with pcDNA3.1, the percentage of cells in the G0/G1 stage was $63.33 \pm 10.88 \%$. In the S stage, this percentage was $27.26 \pm 9.50 \%$, and in the G2/M stage, it declined to $9.4 \pm 1.57 \%$. After the MCF-7 cells were transfected with pcDNA3.1R-Ras38V, the percentage of cells in the G0/ G1 stage was $69.67 \pm 10.66 \%$. In the $\mathrm{S}$ stage this percentage was $18.51 \pm 9.95 \%$, and in the $\mathrm{G} 2 / \mathrm{M}$ stage it was $11.82 \pm 2.92 \%$. The percentage of cells dropped by $32.10 \%$ in the $\mathrm{S}$ stage, when comparing the two groups $(\mathrm{P}<0.01)$ (Fig. 4C). This demonstrated that the cell cycle was restricted at the S stage in the pcDNA3.1 R-Ras38V group; the ability of DNA synthesis decreased, and R-Ras38V arrested cell cycle progression. The migratory capacities of the MCF-7 cell were reduced after transfection. Following comparison of the pcDNA3.1 and pcDNA3.1R-Ras38V groups, the cell transmembrane migratory count declined by $36.11 \%$ on average. When comparing the pcDNA3.1 group with the pcDNA3.1R-Ras group, the cell transmembrane migratory count declined by $2.7 \%$ (Fig. 4D). Thus, R-Ras $38 \mathrm{~V}$ inhibited cell migration in the presence of serum.

Clinical significance of the expression and activation of $R$-Ras in breast cancer. Table I shows that the total protein level of R-Ras was correlated with lymph node metastasis $(\mathrm{P}=0.0474)$ and tumor diameter $(\mathrm{P}=0.0002)$. No correlation with age range $(\mathrm{P}=0.1296)$, histologic types $(\mathrm{P}=0.3803)$ and histologic grades $(\mathrm{P}=0.2358)$ was noted. The relationship between R-Ras-GTP protein expression and clinical pathological characters is summarized in Table II. The results showed that the protein level of R-Ras-GTP was correlated with lymph node metastasis $(\mathrm{P}=0.0171)$. However, there was no correlation with age range, tumor diameter, histologic types and histologic grades.

Since the breast is a hormonal action-targeted organ and the negative expression of the progesterone receptor (PR) and the estrogen receptor (ER) result in poor prognosis (25), within the tumor samples, we also examined PR and ER by immunohistochemistry. PR and ER are located in the nucleus. The positive rate of PR was $55.7 \%$ in 69 of the breast cancer cases whereas the positive rate of ER was $49.92 \%$. In addition, total R-Ras protein levels were also positively associated with ER ( $\mathrm{P}=0.0159)$, while R-Ras-GTP protein expression was negatively associated with $\mathrm{PR}(\mathrm{P}=0.0169)$ and $\mathrm{ER}(\mathrm{P}=0.0119)$.

Table II. Correlation of R-RasGTP protein expression and clinicopathological characteristics of the breast cancer cases.

\begin{tabular}{lccc}
\hline Clinicopathological characteristics & $\begin{array}{c}\text { Reduced group } \\
\text { (53 cases) }\end{array}$ & $\begin{array}{c}\text { Non-reduced group } \\
\text { (16 cases) }\end{array}$ & P-value \\
\hline Age (years) & $50.85 \pm 96.39$ & $49.19 \pm 125.49$ & 0.2839 \\
Diameter of tumor (cm) & $2.24 \pm 0.53$ & $1.90 \pm 0.5$ & 0.0503 \\
Lymph node metastasis & $4.89 \pm 21.04$ & $1.96 \pm 7.93$ & $0.0171^{\text {a }}$ \\
Histological grade & $2.14 \pm 0.12$ & $2.00 \pm 0.13$ & 0.0907 \\
PR & $1.06 \pm 1.13$ & $0.5 \pm 0.67$ & $0.0169^{\text {a }}$ \\
ER & $1.09 \pm 1.12$ & $0.49 \pm 0.64$ & $0.0119^{\text {a }}$
\end{tabular}

PR, progesterone receptor; ER, estrogen receptor. ${ }^{a} \mathrm{P}<0.05$ is considered significant. 


\section{Discussion}

The Ras superfamily is a small $\mathrm{G}$ protein molecular switch that transduces an upstream signal into downstream effectors. The classic Ras proteins include H-Ras, N-Ras and K-Ras. The other proteins include Rap, Ral, R-Ras, Rho, Rin and Rit (26). Since the role of classic Ras in the process of human tumorigenesis has been well established, the R-Ras proteins have been reported to be involved in multiple biological functions, such as induction of cell transformation in fibroblasts, inhibition of cell proliferation in endothelial and smooth muscle cells and spatial modulation of cell migration $(16,27,28)$. Although $\mathrm{R}$-Ras protein expression has been investigated in several types of tumor tissues (i.e., cervical and brain tumor tissues), it has never been previously investigated in breast tumor tissue. In the present study, we systematically investigated the function of R-Ras as a mediator in breast cancer using a unique and comprehensive approach using seven testing methods, which increased the reliability of our experimental results with the capability of cross-validation. For the first time, we analyzed the R-Ras RNA expression level, as well as measured the total protein and activated protein levels using both breast tissue samples and standard breast cell lines.

Based on our experimental results, the median relative $\mathrm{R}$-Ras mRNA ratio was 6-fold higher in normal tissue than this ratio in cancer tissue $(\mathrm{P}=0.00000, \mathrm{P}<0.01)$. Our immunoblot results showed an overexpression of R-Ras protein in normal breast cancer compared with carcinoma; particularly for R-Ras-GTP, we found that it was only activated in 10 of 69 breast cancer tissue samples compared to the paired tumor-adjacent normal tissues (57 of 69). Through the in vivo experiment, we also found that the expression and activity level of R-Ras decreased in breast cancer tissues when compared to normal tissue adjacent to carcinoma. Significant correlations were found between clinicopathological features including tumor diameter and lymph node metastasis. It was negatively correlated to the size of the tumor diameter and the metastatic state. These results suggest that R-Ras expression inhibits the tumor growth, and also significantly inhibits tumor metastasis. With the development of breast cancer, the expression level of R-Ras weakened gradually, and this low R-Ras expression level may cause mammary cells to become cancerous. Regarding prognosis, the amount of R-Ras may also be inversely associated with cancer prognosis (e.g., tumor diameter, metastatic levels). Lower R-Ras protein levels indicate higher amounts of activity in breast cancer.

In order to analyze the effects of R-Ras total protein levels and the protein activity on the biological characteristics of breast cancer cells, R-Ras was overexpressed or overactivated in the MCF-7 cell line, and its effect on the MCF-7 cell biological characteristics was assessed. The results showed that tumor cell proliferation, the invasive ability and movement ability were significantly lower, and the number of cells in the $\mathrm{S}$ phase of the cell cycle was lowered. The results showed that R-Ras38V inhibited cell proliferation, migration and cell cycle progression in the presence of serum. Collectively, our results indicate that R-Ras activation may negatively regulate the transformation of breast epithelial cells, and the loss of activation of R-Ras may be involved in the carcinogenesis of breast cancer.
Notably, our experimental results did not coincide with the results of several studies conducted by other researchers who investigated the correlation between R-Ras protein expression and the development of other types of cancers. In some reports, the $R$-Ras gene was considered to be ubiquitously expressed in all organs and tissues. A number of reports showed that $R$-Ras expression and phosphorylation were correlated with increasing grade of gliomas. The R-Ras mRNA ratios were significantly higher in glioblastoma samples than those in anaplastic astrocytoma tissues, low-grade astrocytoma tissues and normal brain tissues (29). R-Ras reportedly promotes tumor growth of cervical epithelial cells (29). In addition, R-Ras was reported to induce cell transformation in fibroblasts and to induce a more invasive phenotype in breast epithelial T47D cells $(22,26)$. R-Ras was found to increase cervical epithelial cell migratory potential over collagen through a pathway that involves PI3-K (31).

Our experimental results were conflicting. The amount of R-Ras protein showed an inverse association with the risk of breast cancer cell development and metastatic levels. This finding is contradictory to previous observations that showed positive associations between R-Ras protein levels and other types of cancers (28-30). As to the role of R-Ras in breast cancer, we analyzed the problem from three aspects. In regards to the cell lines, previously reported studies used T47D cells and fibroblasts; while in the present study, total R-Ras protein expression was increased only in T47D cells. However, in whole tissue, the total R-Ras protein and R-Ras activity protein expression were decreased. Hence, further investigation and validation on this subject are required by other independent research groups.

For cell proliferation conditions, the biological actions of R-Ras are mediated by multiple effectors. PI3-K-dependent signaling cascades are critical to its function. The estrogen receptor (ER) and progesterone receptor (PR) also mediate signaling events inducing distinct responses in breast cells. In the present study involving 69 cases of breast cancer, the positive rate of ER was $55.7 \%$ and the positive rate of PR was $49.92 \%$. Recent studies demonstrate the existence of crosstalk between EGFR signaling pathways and ER signaling pathways. EGF, IGF-I can modulate the expression and activity of the estrogen receptor- $\alpha$ (ER- $\alpha)$ via the PI 3-K/Akt pathway in ER- $\alpha$-positive breast cancer cell lines. In breast cancer, R-Ras mediates inhibition of insulin signaling associated with the suppression of estrogen action in breast cancer cells. R-Ras participates in cross-talk between estrogen and insulin/IGF-1 signaling (24). Our data showed that R-Ras and R-Ras-GTP participate in estrogen signaling; however, total R-Ras protein levels were also positively associated with ER, while R-Ras-GTP protein expression was negatively associated with PR and ER. In regards to tumor angiogenesis, as a tumor grows in size, it stimulates the formation of new blood vessels (16) in vivo, and the role of R-Ras is an important negative regulator of vascular regeneration and promotes quiescence of vascular cells. The $R$-ras gene disruption in mice rendered these animals susceptible to the excessive proliferative response of neointimal smooth muscle cells to acute arterial injury. Forced expression of activated R-Ras (R-Ras38V) suppressed mitogenic and invasive activities of growth factor-stimulated endothelial cells and arterial smooth 
muscle cells. Hence, further investigation and validation on this subject is required by other independent research groups.

Although the association between R-Ras protein expression or activity and breast cancer development has been investigated by other research groups, this is the first study to use both breast cancer cell lines and breast tumor specimens to comprehensively investigate the association between a new genetic biomarker (R-Ras protein) and breast cancer. Hence, this study has a number of unique characteristics. It used a mixed testing dataset including 12 breast cancer-related cell lines and 69 matched pairs of breast tissue samples acquired from resected breast tumors. We also applied four well-established and commonly acceptable biological testing methods to acquire testing signals and then conducted cross validation of our results using these different testing methods. To the best of our knowledge, this increased the accuracy and reliability of our results. As a result, compared to previous studies, our study provides more comprehensive experimental and data analysis results.

Further research of R-Ras is warranted. It has potential clinical significance in cancer detection and diagnosis. R-Ras protein is a new biomarker with high specificity. Due to this unique characteristic, it can provide valuable complimentary or supplementary diagnostic information along with other existing biomarkers or cancer-related genes. Hence, R-Ras may also be a new predictor of cancer prognosis. Regarding cancer treatment efficacy assessment, increasing R-Ras protein levels following chemotherapy or radiation therapy may indicate favorable response to treatment of the patient. In regards to new cancer drug development, the development and use of drugs that help increase R-Ras protein inside the human body may help cancer prevention and/or reduce the risk of cancer recurrence.

In summary, the present study provides evidence for an important role of R-Ras in breast cancer development. It suggests that deregulation of the balance of protein activity in cells may be an important component of breast tumorigenesis.

\section{Acknowledgements}

The present study was supported in part by the Heilongjiang Province Natural Science Foundation of China (grant no. D200981) and was supported by the National Natural Science Foundation of China (grant no. 81172204). We thank Professor Zaishun Jin for technical support. This study was also supported by the Program for Innovation Team in Science and Technology of the Heilongjiang Province University.

\section{References}

1. Webb CP, Van Aelst L, Wigler MH and Vande Woude GF Signaling pathways in Ras-mediated tumorigenicity and metastasis. Proc Natl Acad Sci USA 95: 8773-8778, 1998.

2. Lowe DG, Capon DJ, Delwart E, et al: Structure of the human and murine R-ras genes, novel genes closely related to ras protooncogenes. Cell 48: 137-146, 1987.

3. Tada M, Kobayashi T, Kontani K and Katada T: Recent progress in the research on small GTP-binding protein. Nihon Yakurigaku Zasshi 130: 373-379, 2007 (In Japanese).

4. Hall A: The cellular functions of small GTP-binding proteins. Science 249: 635-640, 1990.

5. Bourne HR, Sanders DA and Mccormick F: The GTPase superfamily: a conserved switch for diverse cell functions. Nature 348: 125-132, 1990.
6. Self AJ, Caron E, Paterson HF and Hall A: Analysis of R-Ras signaling pathways. J Cell Sci 114: 1357-1366, 2001.

7. Oertli B, Han J, Marte BM, et al: The effector loop and prenylation site of R-Ras are involved in the regulation of integrin function. Oncogene 19: 4961-4969, 2000.

8. Fernandez-Sarabia MJ and Bischoff JR: Bcl-2 associates with the ras related protein R-ras p23. Nature 366: 274-285, 1993.

9. Wang HG, Millan JA, Cox AD, et al: R-Ras promotes apoptosis caused by growth factor deprivation via a Bcl-2 suppressible mechanism. J Cell Biol 129: 1103-1114, 1995.

10. Hughes PE, Oertli B, Han J, et al: R-Ras regulation of integrin function. Methods Enzymol 333: 163-171, 2001.

11. Kinashi T, Katagiri K, Watanabe S, et al: Distinct mechanisms of $\alpha 5 \beta 1$ integrin activation by Ha-Ras and R-Ras. J Biol Chem 275: 22590-22596, 2000.

12. Kwong L, Wozniak MA, Collins AS, et al: R-Ras promotes focal adhesion formation through focal adhesion kinase and $\mathrm{p} 130^{\mathrm{Cas}}$ by a novel mechanism that differs from integrins. Mol Cell Biol 23: 933-949, 2003.

13. Wang B, Zou JX, Ek-Rylander B, et al: R-Ras contains a prolinerich site that binds to $\mathrm{SH} 3$ domains and is required for integrin activation by R-Ras. J Biol Chem 275: 5222-5227, 2000.

14. Furuhjelm J and Peränen J: The C-terminal end of R-Ras contains a focal adhesion targeting signal. J Cell Sci 116: 3729-3738, 2003.

15. Oinuma I, Ito $\mathrm{Y}$, Katoh $\mathrm{H}$ and Negishi M: Semaphorin 4D/ Plexin-B1 stimulates PTEN activity through R-RasGTPaseactivating protein activity, inducing growth cone collapse in hippocampal neurons. J Biol Chem 285: 28200-28209, 2010.

16. Komatsu M and Ruoslahti E: R-Ras is a global regulator of vascular regeneration that suppresses intimal hyperplasia and tumor angiogenesis. Nat Med 11: 1346-1350, 2005.

17. Inuzuka T, Tsuda M, Kawaguchi $\mathrm{H}$, et al: Transcription factor 8 activates R-Ras to regulate angiogenesis. Biochem Biophys Res Commun 379: 510-523, 2009.

18. Sawada J and Komatsu M: Normalization of tumor vasculature by R-Ras. Cell Cycle 11: 4285-4296, 2012.

19. Sawada J, Urakami T, Li F, et al: Small GTPase R-Ras regulates integrity and functionality of tumor blood vessels. Cancer Cell 22: 235-249, 2012.

20. Xu L and Komatsu M: Promoter cloning and characterization of the anti-vascular proliferation gene, R-ras: role of Ets- and Sp-binding motifs. J Biol Chem 284: 2706-2718, 2009.

21. Erdogan M, Pozzi A, Bhowmick N, et al: Transforming growth factor- $\beta$ (TGF- $\beta$ ) and TGF- $\beta$-associated kinase 1 are required for R-Ras-mediated transformation of mammary epithelial cells. Cancer Res 68: 6224-6231, 2008.

22. Keely PJ, Rusyn EV, Cox AD and Parise LV: R-Ras signals through specific integrin $\alpha$ cytoplasmic domains to promote migration and invasion of breast epithelial cells. J Cell Biol 145: 1077-1088, 1999.

23. Yu Y and Feig LA: Involvement of R-Ras and RalGTPases in estrogen-independent proliferation of breast cancer cells. Oncogene 21: 7557-7568, 2002.

24. Yu Y, Hao Y and Feig LA: The R-RasGTPase mediates cross talk between estrogen and insulin signaling in breast cancer cells. Mol Cell Biol 26: 6372-6380, 2006.

25. Ross JS, Linette GP, Stec J, et al: Breast cancer biomarkers and molecular medicine. Expert Rev Mol Diagn 3: 573-585, 2003.

26. Valencla A, Chardin P, Wittinghofer A, et al: The ras protein family: evolutionary tree and role of conserved amino acids. Biochemistry 30: 4637-4648, 1991.

27. Cox AD, Brtva TR, Lowe DG, et al: R-Ras induces malignant, but not morphologic, transformation of NIH3T3 cells. Oncogene 9: 3281-3288, 1994.

28. Wozniak MA, Kwong L, Chodniewicz D, et al: R-Ras controls membrane protrusion and cell migration through the spatial regulation of Rac and Rho. Mol Biol Cell 16: 84-96, 2005.

29. Nakada M, Niska JA, Tran NL, et al: EphB2/R-Ras signaling regulates glioma cell adhesion, growth, and invasion. Am J Pathol 167: 565-576, 2005.

30. Rincón-Arano H, Rosales R, Mora N, et al: R-Ras promotes tumor growth of cervical epithelial cells. Cancer 97: 575-585, 2003.

31. Mora N, Rosales R and Rosales C: R-Ras promotes metastasis of cervical cancer epithelial cells. Cancer Immunol Immunother 56: 535-544, 2007.

32. Wang J, Yao M, Gu J, et al: Blocking HSF1 by dominant- negative mutant to sensitize tumor cell to hyperthermia. Biochem Biophys Res Commun 290: 1454-1461, 2002. 